\title{
Gender Impact on Rheumatoid Arthritis Disease Characteristics in A Cohort of Egyptian Patients
}

\author{
NESREEN S. ABD EL-GHANY, M.D.*; IBRAHEM M. SIAM, M.D.** and AMIRA M. MONIR, Ph.D.*** \\ The Department of Rheumatology and Rehabilitation, Faculty of Medicine, Cairo University*, \\ The Departments of Internal Medicine**, Complementary Medicine***, National Research Center, Cairo
}

\begin{abstract}
Background: Rheumatoid Arthritis (RA) is a chronic inflammatory disease characterized by various extra-articular manifestations and progressive articular damage. It has been a common perception that RA is more severe in females, but the literature is not clear about gender difference regarding RA disease course and prognosis.
\end{abstract}

Aim of Study: To compare between male and female patients with rheumatoid arthritis regarding demographic, clinical characteristics, laboratory features, treatment received as well as the functional disabilities.

Patients and Methods: Two hundred and ten RA patients consecutively recruited from the Rheumatology Department outpatient Clinic, Cairo University Hospitals from December 2017 to May 2018. Patients were divided based on sex and were compared regarding clinical characteristics, laboratory features, medications received, disease activity score 28 (DAS28) and The Stanford Health Assessment Questionnaire (HAQ).

Results: Out of our studied patients $176(83.8 \%)$ were females and $34(16.2 \%)$ males with male to female ratio 5:1. Female RA patients were statistically significant younger age $(p=0.04)$ and statistically significant had lower hemoglobin level $(p=0.00)$, also had higher number of Tender Joint Count (TJC) $(\mathrm{p}=0.4)$, higher DAS28 score $(p=0.3)$, higher health assessment questionnaire score $(p=0.5)$, and more frequently receiving methotrexate $(p=0.3)$ than male RA patients although the differences did not reach statistical significance. On the other hand male RA patients were statistically significant more smoker $(p=0.00)$, and statistically significant more frequently having subcutaneous nodule $(p=0.004)$.

Conclusion: Female RA patients demonstrated slightly worse levels of disease activity and functional disability, although the difference did not reach statistical significance.

Key Words: Male-Female - Rheumatoid arthritis -Egyptian.

Correspondence to: Dr. Nesreen sobhy, E-Mail: Nesreen_sobhy@yahoo.com

\section{Introduction}

RHEUMATOID Arthritis (RA) is an autoimmune inflammatory disease, the inflammatory activity in RA is reflected by different parameters including: Acute phase reactants, number of swollen, tender joint counts, severity of pain, and duration of morning stiffness [1].

Many autoimmune diseases including RA have a striking imbalance between both males and females where females predominating [2]. In RA the sex ratio is typically around 3:1 [3]. Female predominance may be due to genetic (X-linked) and/or hormonal factors [4-9].

The clinical features of RA are not typical in males and females, thus, gender can affect the phenotype of RA [10]

Many studies have suggested that, women with RA have more severe disease and poorer functional status than men [11-18]

However other studies reported that there was no difference observed between male and female RA patients $[\mathbf{1 , 1 9 ]}$.

Aim of work: To explore the difference in demographic, clinical characteristics including disease activity score (DAS28)\}, laboratory features, treatment received as well as the functional disabilities between male and female patients with rheumatoid arthritis.

\section{Patients and Methods}

A cross sectional study enrolled 210 RA patients who fulfilled the 2010 EULAR/ACR classification criteria [20] the patients were consecutively recruited from the Rheumatology Department outpatient 
Clinic, Cairo University Hospitals from December 2017 to May 2018. All patients have been subjected to full history taking, clinical examination and laboratory investigations as well as plain radiography. Disease activity was assessed through DAS28 with three variables [21]. Remission considered if DAS28 <2.6, low disease activity: DAS28 <3.2, moderate disease activity: DAS28 $>3.2$ and $<5.1$, high disease activity: DAS28 $>5.1$ [21]. Functional disability was assessed using The Stanford Health Assessment Questionnaire (HAQ) [22]. The last treatment given to the patients was elucidated. Comparison between male and female patients with RA was done regarding the previous data collected.

\section{Statistical analysis:}

Data were processed and analyzed using the computer program SPSS (The Statistical Package for the Social Science Program) Version 15 for windows (SPSS Inc., Chicago, Illinois, USA). For normally distributed quantitative variables mean and standard deviation were used. The median and percentiles were used to describe non parametric data, while frequency and percentages described qualitative variables. Chi square $\left(\chi^{2}\right)$ test was performed and Fisher exact test was used when appropriate. Mann-Whitney test to estimate differences between non parametric quantitative variables. Value was considered significant at $<0.05$.

\section{Results}

Two hundred and ten RA patients were recruited from Rheumatology and Rehabilitation outpatient clinic Cairo University Hospitals. Their mean age was $45.7 \pm 10.8$ years. Median disease duration was 6 (3-10.2) years. Mean DAS28 was $4.9 \pm 1.2$. Median HAQ was $0.7(0.3-1)$.

Out of our studied patients $176(83.8 \%)$ were females and $34(16.2 \%)$ were males with male to female ratio 5:1. Comparison between male and female patients regarding demographic, clinical, laboratory data, treatment received and HAQ score listed in (Table 1). Female RA patients were statistically significant younger $(p=0.04)$, had higher number of Tender Joint Count (TJC) $(p=0.4)$, higher DAS28 score $(p=0.3)$, higher health assessment questionnaire score $(p=0.5)$, and more frequently receiving methotrexate $(p=0.3)$ but not reaching statistical significance, hemoglobin level $(p=0.00)$ was statistically significant lower than male RA patients. On the other hand male RA patients were statistically significant more smoker $(p=0.00)$, and statistically significant more frequently having subcutaneous nodule $(p=0.004)$.
Table (1): Comparison between male and female RA patients regarding demographic, clinical, laboratory data and treatment received.

\begin{tabular}{llll}
\hline Variable & $\begin{array}{l}\text { Females } \\
(\mathrm{n}=176)\end{array}$ & $\begin{array}{l}\text { Males } \\
(\mathrm{n}=34)\end{array}$ & $\begin{array}{c}p \text { - } \\
\text { value }\end{array}$ \\
\hline Age (years) & $44.9 \pm 10.2$ & $49.9 \pm 13.2$ & 0.04 \\
Disease duration (years) $)$ & $6(3-10.2)$ & $5(1.7-13)$ & 0.2 \\
Smoking & 0 & $15(44.1)$ & 0.00 \\
Subcutaneous nodule & $37(21 \%)$ & $15(44.1 \%)$ & 0.004 \\
SJC & $4(2-7)$ & $5(2-8)$ & 0.5 \\
TJC & $7(4-10)$ & $6(2-9.2)$ & 0.4 \\
DAS28 & $4.97 \pm 1.2$ & $4.74 \pm 1.1$ & 0.3 \\
HAQ & $0.7(0.3-1)$ & $0.6(0.2-1)$ & 0.5 \\
Erosive X-ray & $117(66.5 \%)$ & $22(64.7 \%)$ & 0.8 \\
RF & $142(80.7 \%)$ & $29(85.2 \%)$ & 0.5 \\
ESR (mm/hour) & $45(30-60)$ & $35(22.7-54.5)$ & 0.1 \\
HB (gm/dl) & $11.6 \pm 1.2$ & $13.1 \pm 1.8$ & 0.00 \\
Platelet (platelet/mm $\left.{ }^{3}\right)$ & $312.9 \pm 94.1$ & $305 \pm 116.7$ & 0.6 \\
Steroid & $86(48.8 \%)$ & $19(55.8 \%)$ & 0.4 \\
Methotrexate & $127(72.1 \%)$ & $22(64.7 \%)$ & 0.3 \\
Leflunamide & $51(29 \%)$ & $10(29.4 \%)$ & 0.9 \\
Sulfasalazine & $7(4 \%)$ & $3(8.8 \%)$ & 0.2 \\
\hline
\end{tabular}

HB: Hemoglobin.

\section{Discussion}

RA is a chronic autoimmune inflammatory disease affecting the synovial joints, and with time it leads to significant functional losses due to persistent inflammation in the joints, damage of bone and cartilage, together with the extra-articular manifestations [2].

The incidence of rheumatoid arthritis is 4-5/1 times higher in females below the age of 50, but above the age of 60 years the female/male ratio is only about 2/1 [1], which goes in line with our findings that female/male ratio was $5 / 1$ as the mean age of our patients was $45.7 \pm 10.8$ years.

The QUEST-RA study that analyzed gender difference regarding disease activity, disease characteristics, and treatment in 6004 RA patients revealed that there is no statistical significant difference between both sex regarding RA disease activity, as measured by Disease Activity Score for 28 joints (DAS28) and Health Assessment Questionnaire scores [23]; which was similar to our study findings as DAS28 and HAQ score were higher in females but not reaching statistical significance ( $p=0.3$ and 0.5 respectively).

Women with RA scored significantly higher in subjective, but not objective measures of disease activity, furthermore females in general had a lower pain threshold than males [24-27], which may explain our findings as female patients had higher TJC and lower SJC compared to men subcutaneous nodule 
was statistically significant higher in males with RA ( $p=0.004)$ which agreed with Weyand et al., as he found that rheumatoid nodule found more frequently in men than women with RA $(p=0.001)$ [28].

Many epidemiological studies identified smoking as a risk factor for RA in male and also in female [29-32]; even with light smoking [31].

We found that smoking was statistically significantly more frequent in male $(p=0.00)$, and as smoking is known to be associated with production of RF $[33,34]$; so this may explain the higher percentage of RF positivity in males of our studied patients compared to females although it did not reach statistical significance. Other study supports our findings [1]. Premenopausal women have mean hemoglobin levels approximately $12 \%$ lower than age $\&$ race matched men [35] which may explain the lower hemoglobin level in our studied female patients compared to male patients.

Radiographs provide a measure of the degree of structural damage of RA [36]. We did not find any difference regarding erosive changes on radiograph between both sexes. Several studies reported similar results $[\mathbf{1 2 , 1 9 , 3 7 , 3 8 ]}$

No significant differences was found regarding treatment received between male and female RA patients which was similar to other study [23].

\section{Conclusion:}

The general perception that females have a more severe disease than males was confirmed although the differences were not that clear. Further studies concerning the possible influence of gender on the clinical status and disease activity measures of RA appears to be of value.

\section{References}

1- KVIEN T.K., UHLIG T., ODEGARD S. and HEIBERG M.S.: Epidemiological Aspects of Rheumatoid Arthritis the Sex Ratio. Ann. N.Y. Acad. Sci., 1069: 212-22, 2006.

2- VAN VOLLENHOVEN R.F.: Sex differences in rheumatoid arthritis: More than meets the eye. B.M.C. Med., 7: 12, 2009.

3- WOLFE A.M., KELLGREN J.H. and MASI A.T.: The epidemiology of rheumatoid arthritis: A review. Incidence and diagnostic criteria. Bull Rheum. Dis., 19: 524-9, 1968.

4- VAN VOLLENHOVEN R.F. and McGUIRE J.L.: Estrogen, Progesterone, and Testosterone: Can they be used to treat Autoimmune Diseases? Cleveland Clinic J. Med., 61: 276, 1994.

5- CUTOLO M., VILLAGGIO B., SERIOLO B., MONTAGNA P., CAPELLINO S., STRAUB R.H. and SULLI
A.: Synovial fluid estrogens in rheumatoid arthritis. Autoimmun. Rev., 3: 193-8, 2004.

6- WILDER R.L.: Hormones, pregnancy, and autoimmune diseases. Ann. N. Y. Acad. Sci., 840: 45-50, 1998.

7- CUTOLO M., SULLI A., CAPELLINO S., VILLAGGIO B., MONTAGNA P., SERIOLO B. and STRAUB R.H.: Sex hormones influence on the immune system: Basic and clinical aspects in autoimmunity. Lupus, 13: 635-8, 2004.

8- OLSEN N.J. and KOVACS W.J.: Hormones, pregnancy, and rheumatoid arthritis. J. Gend. Specif. Med., 5: 2837, 2002.

9- O'BRIEN S.M., FITZGERALD P., SCULLY P., LANDERS A., SCOTT L.V. and DINAN T.G.: Impact of gender and menstrual cycle phase on plasma cytokine concentrations. Neuroimmunomodulation, 14: 84-90, 2007.

10- WEYAND C.M., XIE C. and GORONZY J.J.: Homozygosity for HLA DRB, alleles select for extra articular manifestation in rheumatoid arthritis. J. Clin. Invest., 89: 2033-9, 1992.

11-FORSLIND K., HAFSTROM I., AHLMEN M. and SVENSSON B.: Sex: A major predictor of remission in early rheumatoid arthritis? Ann. Rheum. Dis., 66: 46-52, 2007.

12- TENGSTRAND B., AHLMEN M. and HAFSTROM I.: The influence of sex on rheumatoid arthritis: A prospective study of onset and outcome after 2 years. J. Rheumatol., 31: 214-22, 2004.

13- SYMMONS D.P.: Epidemiology of rheumatoid arthritis: Determinants of onset, persistence and outcome. Best Pract. Res. Clin. Rheumatol., 16: 707-22, 2002.

14- KUIPER S., VAN GESTEL A.M., S WINKELS H.L., De BOO T.M., Da SILVA J.A. and VAN RIEL P.L.: Influence of sex, age, and menopausal state on the course of early rheumatoid arthritis. J. Rheumatol., 28: 1809-16, 2001.

15- Da SILVA J.A. and HALL G.M.: The effects of gender and sex hormones on outcome in rheumatoid arthritis. Baillieres Clin. Rheumatol., 6: 196-219, 1992.

16- MANCARELLA L., BOBBIO-PALLAVICINI F., CECCARELLI F., et al.: Good clinical response, remission, and predictors of remission in rheumatoid arthritis patients treated with tumor necrosis factor-alpha blockers: The GISEA study. J. Rheumatol., 34: 1670-3, 2007.

17- HYRICH K.L., WATSON K.D., SILMAN A.J. and SYMMONS D.P.: British Society for Rheumatology Biologics Register. Predictors of response to anti-TNF-a therapy among patients with rheumatoid arthritis: Results from the British Society for Rheumatology Biologics Register. Rheumatology (Oxford), 45: 1558-65, 2006.

18- YAMANAKA H., TANAKA Y., SEKIGUCHI N., et al.: Retrospective clinical study on the notable efficacy and related factors of infliximab therapy in a rheumatoid arthritis management group in Japan (RECONFIRM). Mod. Rheumatol., 17: 28-32, 2007.

19- GOSSEC L., BARO-RIBA J., BOZONNAT M.C., et al.: Influence of sex on disease severity in patients with rheumatoid arthritis. J. Rheumatol., 32: 1448-51, 2005.

20- ALETAHA D., NEOGI T., SILMAN A., FUNOVITS J., FELSON D., BINGHAM C., BIRNBAUM N., BURM- 
ESTER G., BYKERK V., MARC D., BERNARD C., KAREN H., MAXIME D., PAUL E., GIANFRANCO F., JOHANNA M., KATHRYN H., TOM W., ARTHUR K., JONATHAN K., TORE K. and TIMOTHY L.: Rheumatoid Arthritis Classification Criteria An American College of Rheumatology/European League Against Rheumatism Collaborative Initiative. Arthritis \& rheumatism, 62: 256981, 2010.

21- PREVOO M., VAN'T M. and KUPER H.: Modified disease activity scores that include twenty-eight-joint counts. Development and validation in a prospective longitudinal study of patients with rheumatoid arthritis. Arthritis \& Rheumatism, 38 (1): 44-8, 1995.

22- BONNIE B. and JAMES F.: The Stanford Health Assessment Questionnaire: Dimensions and Practical Applications. Health and Quality of Life Outcomes, 1: 20, 2003.

23- SOKKA T., TOLOZA S., CUTOLO M., et al.: Women, men, and rheumatoid arthritis: Analyses of disease activity, disease characteristics, and treatments in the QUEST-RA study. Arthritis Res. Ther., 11 (1): R7, 2009.

24- RILEY J.L., 3 rd, ROBINSON M.E., WISE E.A., PRICE D.D.: A meta-analytic review of pain perception across the menstrual cycle. Pain, 81: 225-35, 1999.

25- UNRUH A.M.: Gender variations in clinical pain experience. Pain, 65: 123-67, 1996.

26- BINGEFORS K. and ISACSON D.: Epidemiology, comorbidity, and impact on health-related quality of life of self-reported headache and musculoskeletal pain-a gender perspective. Eur. J. Pain, 8: 435-50, 2008.

27- SMITH Y.R., STOHLER C.S., NICHOLS T.E., BUELLER J.A., KOEPPE R.A. and ZUBIETA J.K.: Pronociceptive and antinociceptive effects of estradiol through endogenous opioid neurotransmission in women. J. Neurosci., 26: 5777-85, 2006.

28- WEYAND C.M., SCHMIDT D., WAGNER U., et al.: The influence of sex on the phenotype of rheumatoid arthritis. Arthritis Rheum., 41: 817-22, 1998.
29- COSTENBADER K.H., FESKANICH D., MANDL L.A. and KARLSON E.W.: Smoking intensity, duration, and cessation, and the risk of rheumatoid arthritis in women. Am. J. Med., 119: 503.e1-9, 2006.

30- SUGIYAMA D., NISHIMURA K., TAMAKI K., TSUJI G., NAKAZAWA T., MORINOBU A. and KUMAGAI S.: Impact of smoking as a risk factor for developing rheumatoid arthritis: A meta-analysis of observational studies. Ann. Rheum. Dis., 69: 70-81, 2010.

31- Di GIUSEPPE D., DISCACCIATI A., ORSINI N. and WOLK A.: Cigarette smoking and risk of rheumatoid arthritis: A dose-response meta-analysis. Arthritis Res. Ther., 16: R61, 2014.

32- KRISHNAN E., SOKKA T. and HANNONEN P.: Smoking-gender interaction and risk for rheumatoid arthritis. Arthritis Res. Ther., 5: R158-R162, 2003.

33- JONSSON T., THORSTEINSSON J. and VALDIMARSSON H.: Does smoking stimulate rheumatoid factor production in non-rheumatic individuals? APMIS, 106: 970-4, 1998.

34- TUOMI T., HELIOVAARA M., PALOSUO T. and AHO K.: Smoking, lung function, and rheumatoid factors. Ann. Rheum. Dis., 49: 753-6, 1990.

35- MURPHY W.G.: The sex difference in haemoglobin levels in adults-mechanisms, causes, and consequences. Blood Rev., 28 (2): 41-7, 2014.

36- PINCUS T. and SOKKA T.: Quantitative measures for assessing rheumatoid arthritis in clinical trials and clinical care. Best Pract. Res. Clin. Rheumatol., 17: 753-81, 2003.

37- WOLFE F. and SHARP J.T.: Radiographic outcome of recent-onset rheumatoid arthritis: A 19-year study of radiographic progression. Arthritis Rheum., 41: 1571-82, 1998.

38- LUUKKAINEN R., KAARELA K., ISOMÄKI H., MARTIO J., KIVINIEMI P., RÄSÄNEN J. and SARNA S.: The prediction of radiological destruction during the early stage of rheumatoid arthritis. Clin. Exp. Rheumatol., 1: 295-8, 1983. 


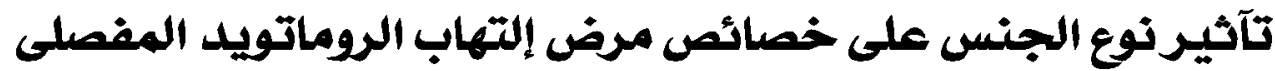

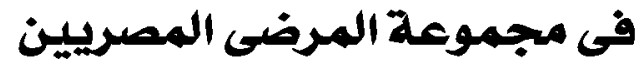

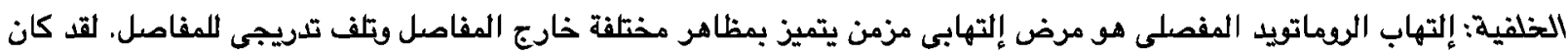
تصود شائع آن إلتهاب الروماتويد المفصلى آكثر حدة فى الإناث، ولكن المطبوعات ليست واضحة حول الفرق بين الجنسين فيما يتعلق بمسار المرض.

الهدف من العمل: مقارنة بين الذكو والإناث من المرضى الذين يعانون من إلتهاب الروماتويد المفصلى فيما يتعلق بالخصائص الديموغرافية

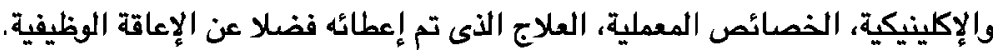

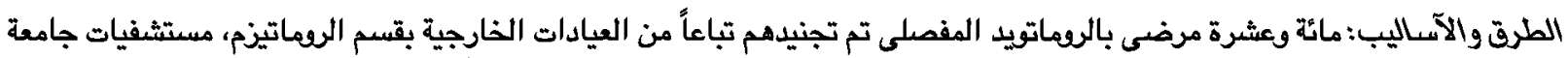

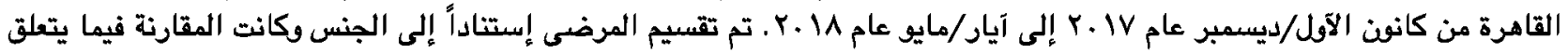

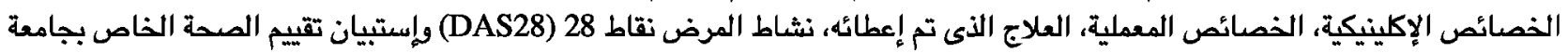

ستانفود (HAQ)

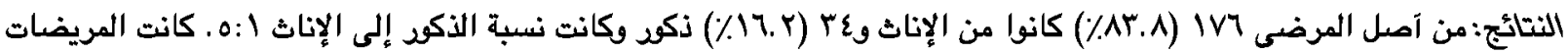

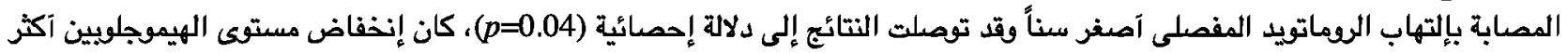

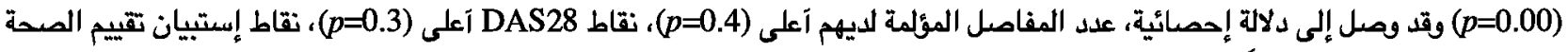

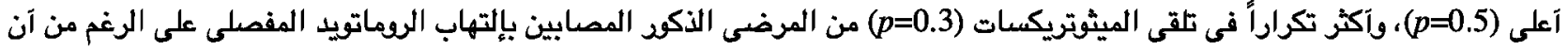

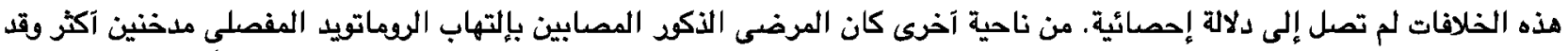

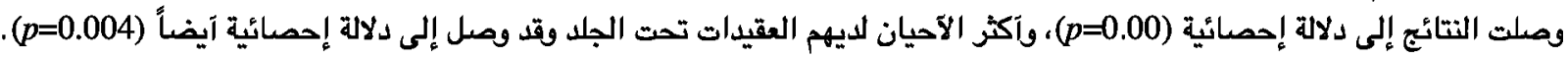

الخلاصة: المريضات المصابين بمرض الروماتويد المفصلى آظهرن مستويات آسواً تليلا من ناحية نشاط المرض والإعاقة الوظيفية، على 